\title{
Complexation of thorium(IV) with 2-furoic acid and 2-thenoic acid in aqueous solution
}

\author{
Arturo Bismondo, ${ }^{a}$ Plinio Di Bernardo, ${ }^{*, b}$ PierLuigi Zanonato, ${ }^{b}$ Jun Jiang ${ }^{c}$ and \\ Linfeng $\operatorname{Rao}^{\mathrm{c}}$ \\ ${ }^{a}$ Istituto di Chimica Inorganica e delle Superfici del C.N.R. of Padova, Corso Stati Uniti \\ 4, 35127, Padova, Italy \\ ${ }^{b}$ Dipartimento di Chimica Inorganica Metallorganica ed Analitica, Università di Padova, \\ via Loredan 4, 35131, Padova, Italy,E-mail: plinio.dibernardo@unipd.it \\ ${ }^{c}$ Glenn T. Seaborg Center, Lawrence Berkeley National Laboratory, Berkeley, CA 94720, \\ U.S.A.
}

\section{Graphical Content Entry}

Stability constants of Th(IV)/furoate and Th(IV)/thenoate complexes and enthalpy of complexation were determined by potentiometry and calorimetry. Results from FT Raman and Extended X-Ray Absorption Fine Structure (EXAFS) helped to clarify the coordination modes in the complexes.

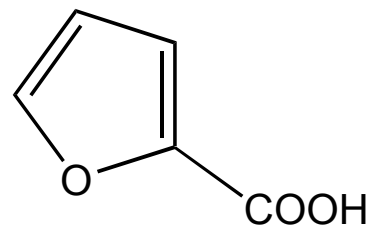

2-Furoic Acid

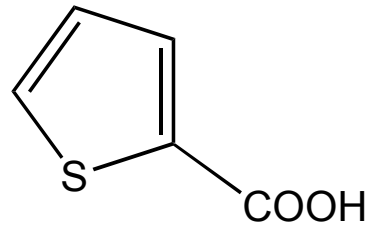

2-Thenoic Acid

\footnotetext{
* Corresponding author: plinio.dibernardo@unipd.it
} 


\title{
Complexation of thorium(IV) with 2-furoic acid and 2-thenoic acid in aqueous solution
}

\author{
Arturo Bismondo, ${ }^{a}$ Plinio Di Bernardo,,${ }^{*}$ p PierLuigi Zanonato, ${ }^{b}$ Jun Jiang ${ }^{c}$ and \\ Linfeng Rao ${ }^{\mathrm{c}}$ \\ ${ }^{a}$ Istituto di Chimica Inorganica e delle Superfici del C.N.R. of Padova, Corso Stati Uniti \\ 4, 35127, Padova, Italy \\ ${ }^{b}$ Dipartimento di Chimica Inorganica Metallorganica ed Analitica, Università di Padova, \\ via Loredan 4, 35131, Padova, Italy, E-mail: plinio.dibernardo@unipd.it \\ ${ }^{c}$ Glenn T. Seaborg Center, Lawrence Berkeley National Laboratory, Berkeley, CA 94720, \\ U.S.A.
}

\section{Summary}

Complexation of Th(IV) with 2-furoic acid $\left(\mathrm{C}_{4} \mathrm{H}_{3} \mathrm{OCOOH}\right)$ and 2-thenoic acid $\left(\mathrm{C}_{4} \mathrm{H}_{3} \mathrm{SCOOH}\right)$ in $1.0 \mathrm{~mol} \mathrm{dm}^{-3} \mathrm{NaClO}_{4}$ was studied at $25^{\circ} \mathrm{C}$. The formation constants of successive complexes $\mathrm{ThL}_{\mathrm{j}}^{(4-\mathrm{j})^{+}}$, where $\mathrm{L}$ stands for the furoate or thenoate anion and $\mathrm{j}=1$ - 3 for 2-furoic acid and $\mathrm{j}=1$ - 2 for 2-thenoic acid, and corresponding molar enthalpies of complexation were determined by potentiometry and calorimetry. Spectroscopic techniques, including FT Raman and Extended X-Ray Absorption Fine Structure (EXAFS), were used to acquire further information on the interaction between Th(IV) and the ligands. Both the thermodynamic and spectroscopic data are consistent with the formation of $\mathrm{ThL}_{\mathrm{j}}^{(4-\mathrm{j})+}$ complexes, in contrast to earlier results in the literature that suggest the protonated complexes, $\mathrm{ThL}_{4} \mathrm{H}_{2}{ }^{2+}$ and $\mathrm{ThL}_{3} \mathrm{H}_{2}{ }^{3+}$, are dominant under the experimental conditions. The binding strength of furoic acid and thenoic acid with Th(IV) is discussed in conjunction with the data for other monocarboxylic acids.

\footnotetext{
* Corresponding author: plinio.dibernardo@unipd.it
} 


\section{Introduction}

Complexation of actinide elements with carboxylic acids has been a subject of study for many years, both for fundamental understanding of the nature of actinide coordination and for applications in actinide separations. As a result, a considerable amount of thermodynamic data has been accumulated concerning the nature and stability of the complexes, and enthalpy and entropy of the complexation. ${ }^{1}$ In recent years, significant interest in this field has been stimulated by the activities of the environmental management of nuclear wastes. Some carboxylic acids exist in the nuclear wastes and affect the chemical behavior of actinides in waste processing and in environmental migration by forming complexes. Other carboxylic acids, though they may not exist in the nuclear wastes, are of interest because the studies help to demonstrate regularities and develop correlations that could provide insight into the nature of the actinide complexes.

As hard acids, the bonding of actinide cations to ligands in aqueous solution is predominantly ionic and strongly electrostatic in nature. They interact more effectively with ligands with hard base donor atoms such as oxygen than with soft base donor atoms such as sulfur. Since proton is also a hard acid, a relation is expected between the protonation of the carboxylates and their complexation with actinide cations. This implies that the binding strength of carboxylates with actinides, measured by the stability constants of the complexes, may parallel the basicity of the carboxylates, measured by the $\mathrm{pKa}$ of the ligand $\left(\log \beta-\mathrm{pK}_{\mathrm{a}}\right.$ correlation). Such correlation has been demonstrated by the large amount of data for uranyl-carboxylate complexation. ${ }^{2}$ However, data for Th(IV) are much more limited. For the complexation of Th(IV) with monocarboxylates, few data are available for ligands with $\mathrm{pK}_{\mathrm{a}}$ ranging from 2.5 to 4.0. Thus, one objective 
of the present study is to select appropriate monocarboxylate ligands with $\mathrm{pKa}$ in this region, measure the stability constants of their complexes with $\mathrm{Th}(\mathrm{IV})$, and test the $\log \beta$ - $\mathrm{pK}_{\mathrm{a}}$ correlation for Th(IV). 2-Furoic acid and 2-thenoic acid, both have $\mathrm{pK}_{\mathrm{a}}$ values in this region, are selected.

A literature survey shows that the data on the complexation of Th(IV) with 2-furoic acid and 2-thenoic acid are extremely scarce. One paper was previously published in this journal on the complexation in aqueous solutions at low $\mathrm{pH}(\mathrm{pH}<2.7){ }^{3}$ Formation constants of complex species, including simple complexes $\left(\mathrm{ThL}^{3+}, \mathrm{ThL}_{2}{ }^{2+}\right.$ and $\left.\mathrm{ThL}_{4}\right)$ and protonated complexes (e.g., $\mathrm{ThL}_{4} \mathrm{H}_{2}{ }^{2+}$ and $\mathrm{ThL}_{3} \mathrm{H}_{2}{ }^{3+}$ ), are calculated from potentiometric data. A critical review of the results from this work indicate that high uncertainty must be associated with the constants for the simple complexes $\left(\mathrm{ThL}^{3+}, \mathrm{ThL}_{2}{ }^{2+}\right.$ and $\left.\mathrm{ThL}_{4}\right)$ since these species were never in significant amounts in the fit, ranging from only $1 \%$ to $15 \%{ }^{3}$ According to the results from this work, the protonated complexes $\left(\mathrm{ThL}_{4} \mathrm{H}_{2}{ }^{2+}\right.$ and $\mathrm{ThL}_{3} \mathrm{H}_{2}{ }^{3+}$ ) were dominant under the experimental conditions. This seems inconsistent with the high charge density of $\mathrm{Th}^{4+}$ that would induce the deprotonation of the acid and facilitate the formation of deprotonated complexes. In fact, literature data indicate that $\mathrm{Th}(\mathrm{IV})$ forms exclusively simple complexes $\left(\mathrm{ML}_{\mathrm{j}}, \mathrm{j}=1-5\right)$ with monocarboxylate anions. ${ }^{1}$ Obviously, the speciation of Th(IV) in the presence of furoic or thenoic acids remains uncertain. Besides, there are no data on the enthalpy and entropy of complexation of Th(IV) with furoic and thenoic acids in the literature. It is the second objective of the present work to obtain reliable formation constants and other thermodynamic parameters (enthalpy and entropy) for the complex species, providing further insight into the speciation of the Th(IV)/furoic acid and Th(IV)/thenoic acid 
systems. Furthermore, a comparison of the thermodynamic parameters between furoate, thenoate and other monocarboxylates could reveal whether the ether oxygen or sulfur participates in the complexation with Th(IV).

\section{Experimental}

\subsection{Chemicals}

All chemicals were reagent grade or higher. Distilled and deionized water was used in preparations of all the solutions. Sodium hydroxide solutions, free from carbonate, were standardized against $1.005 \mathrm{~mol} \mathrm{dm}^{-3}$ hydrochloric acid (Aldrich, ACS volumetric standard). The standardized sodium hydroxide solution was in turn used to determine the concentrations of perchloric acid by potentiometry.

2-Furoic and 2-thenoic acids (Aldrich, $>98 \%$ and $>99 \%$, respectively) were purified by re-crystallization from water/methanol. ${ }^{4}$ Buffer solutions of sodium furoate/furoic acid and sodium thenoate/thenoic acid were prepared by adding calculated amounts of sodium hydroxide into solutions of the acids. It was found that the solubility of thenoic acid is not very high in water $\left(<50 \mathrm{mmol} \mathrm{dm}^{-3}\right)$ and sodium thenoate is not very stable in a basic solution for a long time. For the latter reason, the solutions of thenoic acid were always freshly prepared from the solid and used within two days.

The stock solution of $\mathrm{Th}(\mathrm{IV})$ perchlorate was prepared from $\mathrm{Th}(\mathrm{IV})$ nitrate as follows. Th( $\left(\mathrm{NO}_{3}\right)_{4}\left(4 \mathrm{H}_{2} \mathrm{O}\right)$ was dissolved in water. $\mathrm{Th}(\mathrm{OH})_{4}(\mathrm{~s})$ was precipitated by adding $\mathrm{NaOH}$. The precipitate was centrifuged, washed with water and re-dissolved with perchloric acid. The precipitation and dissolution were repeated for three times. The 
concentrations of thorium and free perchloric acid in the stock solution were determined by EDTA titration complexometry ${ }^{5}$ and Gran's potentiometric method, ${ }^{6}$ respectively.

The ionic strength of all the solutions used in potentiometry and calorimetry was adjusted to $1.0 \mathrm{~mol} \mathrm{dm}{ }^{-3}$ at $25^{\circ} \mathrm{C}$ by adding appropriate amounts of sodium perchlorate.

\subsection{Potentiometry}

Potentiometric titrations were carried out to determine the protonation constants of furoate and thenoate and the formation constants of their complexes with Th(IV). The experiments were conducted at $25{ }^{\circ} \mathrm{C}$ with a constant temperature titration setup. Detailed descriptions of the apparatus and the procedures have been previously provided. ${ }^{7,8,9}$ The original electrode internal solution and bridge solution $\left(3.0 \mathrm{~mol} \mathrm{dm}^{-3} \mathrm{KCl}\right)$ were replaced with solutions of $0.05 \mathrm{~mol} \mathrm{dm}^{-3} \mathrm{NaCl} / 0.95 \mathrm{~mol} \mathrm{dm}^{-3} \mathrm{NaClO}_{4}$ and $1.0 \mathrm{~mol} \mathrm{dm}^{-3} \mathrm{NaClO}_{4}$, respectively, to avoid clogging of the electrode frit glass septum by precipitation of $\mathrm{KClO}_{4}$. The electrode (Metrohm 60219.100) was calibrated before each titration by titrating standard perchloric acid solution with standard $\mathrm{NaOH}$ solution. The calculated hydrogen ion concentrations were used to convert the emf readings to hydrogen ion concentrations. All the emf data were corrected for a small contribution from the liquid junction potential $E_{\mathrm{j}, \mathrm{H}^{+}}$of the hydrogen ion. Corrections for the junction potential of hydroxide ion were not necessary in these experiments.

The protonation of furoate and thenoate was studied by titrating the solutions of furoic acid $\left(7-21 \mathrm{mmol} \mathrm{dm}^{-3}\right)$ or thenoic acid $\left(9-20 \mathrm{mmol} \mathrm{dm}^{-3} \mathrm{HL}\right.$ or a buffered solution of $48 \mathrm{mmol} \mathrm{dm}{ }^{-3} \mathrm{HL} / 48 \mathrm{mmol} \mathrm{dm}{ }^{-3} \mathrm{NaL}$ ) with $100 \mathrm{mmol} \mathrm{dm}{ }^{-3} \mathrm{NaOH}$. The complexation of Th(IV) with furoate and thenoate was studied by titrating a solution of thorium perchlorate $\left(3-32 \mathrm{mmol} \mathrm{dm}^{-3}\right)$ with buffer solutions of furoic and thenoic acids. 
Usually $4-5$ titrations were conducted for the protonation or complexation. The initial volume of the test solutions was usually $20 \mathrm{~cm}^{3}$ at $25{ }^{\circ} \mathrm{C}$. The computer program Superquad ${ }^{10}$ was used to calculate the protonation constants, $\beta_{\mathrm{H}}$, and the formation constants of thorium complexes, $\beta_{\mathrm{j}, \mathrm{M}}$.

\subsection{Calorimetry}

Calorimetric titrations were carried out to determine the enthalpy of protonation of furoate and thenoate, and the enthalpy of complexation with Th(IV). The experiments were conducted with a computer-controlled calorimeter (Tronac model 450). Detailed description of the apparatus was provided elsewhere. ${ }^{11,12}$ The precision and accuracy of the instrument were checked by titration of tris(hydroxymethyl)aminomethane (THAM) with a standard $\mathrm{HCl}$ solution in water. The protonation enthalpy $\left(\Delta \mathrm{H}^{0}\right)$ of THAM was found to be $-47.58 \mathrm{~kJ} \mathrm{~mol}^{-1}$, in excellent agreement with the value of $-47.53 \pm 0.13 \mathrm{~kJ}$ $\mathrm{mol}^{-1}$ in the literature. ${ }^{1}$ The concentrations of the cup solutions and the titrants in the calorimetric titrations were similar to those in the potentiometric titrations, except that the initial volume of the cup solution was always $20 \mathrm{~cm}^{3}$ at $25{ }^{\circ} \mathrm{C}$. The enthalpies of protonation and complexation were calculated with the computer program Letagrop ${ }^{13}$ as previously described.

\subsection{FT Raman spectroscopy}

FT Raman spectroscopy was used to acquire further information on the interaction between Th(IV) and furoic acid. The spectra were recorded under dry-air purge at $25^{\circ} \mathrm{C}$ on a Nicolet Nexus E.S.P. FT-IR spectrometer equipped with a Raman module. To obtain spectra of good quality, 2000 scans were performed with $4 \mathrm{~cm}^{-1}$ resolution. The spectrum of the solvent was numerically subtracted from the spectra of the sample solutions. For 
quantitative analysis, the intensities of the peaks were evaluated by the deconvolution of the difference spectra. A Marquardt non-linear regression program was used to deconvolute the spectra into individual line bands assuming Lorentzian line shape. Due to the intrinsic difficulties in controlling all the experimental parameters in the FT-Raman experiment, great care was taken to maintain the same experimental conditions to obtain reproducible spectra. Nevertheless, the data from the Raman experiments may not be as quantitative as desired and are used in this work only to provide further information to help understand the coordination mode in the Th(IV)/furoate complexes.

\subsection{Extended X-ray Absorption Fine Structure (EXAFS) spectroscopy}

EXAFS experiments were conducted with $\mathrm{ThO}_{2}(\mathrm{~s})$, a solution of $\mathrm{Th}(\mathrm{IV})$ in perchloric acid $\left(\left[\mathrm{Th}^{4+}\right]=0.05 \mathrm{~mol} \mathrm{dm}^{-3}\right.$ and $\left.\left[\mathrm{HClO}_{4}\right]=1.0 \mathrm{~mol} \mathrm{dm}^{-3}\right)$, and a solution of Th(IV) in the presence of furoic acid $\left(\left(\left[\mathrm{Th}^{4+}\right]=0.084 \mathrm{~mol} \mathrm{dm}^{-3},\left[\mathrm{HClO}_{4}\right]=0.272 \mathrm{~mol} \mathrm{dm}^{-3}\right.\right.$ and [furoic acid] $=0.372 \mathrm{~mol} \mathrm{dm}^{-3}$ ). The solid sample was prepared by mixing appropriate amounts of $\mathrm{ThO}_{2}(\mathrm{~s})$ with boron nitride and loading the mixture to an aluminum holder with a rectangular opening of $20 \mathrm{~mm} \times 2 \mathrm{~mm}$ and a thickness of $0.5-1 \mathrm{~mm}$. The solution samples were prepared by sealing approximately $2 \mathrm{~cm}^{3}$ of each solution in a polyethylene tube (5 $\mathrm{mm}$ i.d.). The solid sample holder and the solution sample tubes were mounted on an aluminum sample positioner with Scotch tape for the EXAFS experiments.

Thorium L3-edge EXAFS spectra were collected at the Stanford Synchrotron Radiation Laboratory (SSRL) on wiggler beamline 4-1 under normal ring operating conditions $(3.0 \mathrm{GeV}, 50-100 \mathrm{~mA})$. The EXAFS data were collected in both the transmission (using argon-filled ionization chambers) and the fluorescence modes (using a four-element Ge-detector ${ }^{14}$ ), up to $\mathrm{k} \sim 15 \AA^{-1}$. Eight scans were performed for each 
sample. Energy calibration was based on assigning the first inflection point of the absorption edge for thorium dioxide $\left(\mathrm{ThO}_{2}\right)$ to $16300 \mathrm{eV}$. The EXAFS spectra (k-window between 2.5 and 11.0) were fitted with the R-space X-ray Absorption Package (RSXAP), ${ }^{15}$ using parameterized phase and amplitude functions generated by the program $\mathrm{FEFF}^{16}$ with the reference crystal structures of $\mathrm{ThO}_{2}$ and $\mathrm{Na}_{6} \mathrm{Th}\left(\mathrm{CO}_{3}\right)_{5}\left(\mathrm{H}_{2} \mathrm{O}\right)_{12} .{ }^{17}$ Standard scattering paths, including the single scattering Th-O, Th-C and Th-Th were calculated from the reference structure and included in the data analysis.

\section{Results and discussion}

\subsection{Protonation of furoate and thenoate}

The calculated protonation constants, Gibbs free energy, enthalpy, and entropy of protonation are given in Table 1 . The value of $\log \beta_{\mathrm{H}}$ for furoate agrees very well with that in the literature, but $\log \beta_{\mathrm{H}}$ for thenoate differs significantly from the value in the literature. The enthalpy of protonation for either ligand is small and positive, typical of carboxylic acids $\left(\Delta \mathrm{H} \sim 0-5 \mathrm{~kJ} \mathrm{~mol}^{-1}\right.$ at $\left.25{ }^{\circ} \mathrm{C}\right)$. The entropy of protonation for furoate and thenoate $\left(66-68 \mathrm{~J} \mathrm{~K}^{-1} \mathrm{~mol}^{-1}\right)$ is also in agreement with that for most of monocarboxylic acids $\left(\Delta \mathrm{S} \sim 60-90 \mathrm{~J} \mathrm{~K}^{-1} \mathrm{~mol}^{-1}\right.$ at $\left.25^{\circ} \mathrm{C}\right) .{ }^{1}$

\subsection{Complexation of $\mathrm{Th}(\mathrm{IV})$ with furoate and thenoate}

The potentiometric titration data for the complexation of Th(IV) with furoate and thenoate are presented in Figure 1, in the form of $\bar{n}$ vs. $\log [L] \cdot \bar{n}$ is the average number of the ligand ions bound to each thorium ion as calculated by the equation:

$$
\bar{n}=\left\{C_{\mathrm{L}}-[\mathrm{L}]\left(1+\beta_{\mathrm{H}}\left[\mathrm{H}^{+}\right]\right)\right\} / C_{\mathrm{M}}
$$


where $C_{\mathrm{L}}$ and $C_{\mathrm{M}}$ are the concentrations of total ligand and $\mathrm{Th}(\mathrm{IV})$ in solution and [L] is the concentration of the free ligand. $\beta_{\mathrm{H}}$ is the protonation constant obtained from the protonation titration: $\beta_{\mathrm{H}}=\left[\mathrm{HL}^{-}\right] /\left(\left[\mathrm{H}^{+}\right]\left[\mathrm{L}^{-}\right]\right)$. Data analysis by the Superquad program indicates that the best fit was obtained by assuming the formation of successive $\mathrm{ML}_{\mathrm{j}}$ complexes:

$$
\mathrm{Th}^{4+}+j \mathrm{~L}^{-} \leftrightarrows \mathrm{ThL}_{\mathrm{j}}^{(4-\mathrm{j})^{+}}
$$

where $j=1,2$ and 3 for furoate and $j=1$ and 2 for thenoate. The range of $\log \left[\mathrm{H}^{+}\right]$in the titrations was from -2.6 to -1.5 and from -1.9 to -1.4 for the $\mathrm{Th}(\mathrm{IV}) /$ furoate and Th(IV)/thenoate systems, respectively. Calculations with the minimization program show that the hydrolysis of Th(IV) under the experimental conditions is negligible. As a result, the hydrolysis reactions of Th(IV) were not included in the final data analysis.

The calculated formation constants and Gibbs free energy of complexation are given in Table 1. Including the third Th(IV)/furoate complex in the calculation improves the overall fit, but has minor effect on the constants for the first and the second complexes. Due to the formation of solid compounds, the highest value of $\bar{n}$ was $\sim 2.3$ and 0.7 in the $\mathrm{Th}(\mathrm{IV}) /$ furoate and $\mathrm{Th}(\mathrm{IV}) /$ thenoate systems, respectively. As a result, formation constants of three successive mononuclear complexes were calculated for the furoate system, while the formation constants of only two such complexes were calculated for the thenoate system. Simulated potentiometric titration curves calculated with these constants are in good agreement with the experimental points (Figure 1). The maximum percentage of the third complex was about $35 \%$ for the Th(IV)/furoate system, while that of the second complex in the Th(IV)/thenoate system was less than $10 \%$ in the more diluted thorium solutions. 
The data of the calorimetric titrations are shown in Figure 2, in the form of $\Delta h_{\mathrm{v}}$ vs. $\bar{n}$, where $\Delta h_{\mathrm{v}}$ is the total heat per mole of Th(IV) and is calculated by dividing the net reaction heat with the number of moles of thorium in the calorimeter vessel. As previously mentioned, formation of solid compounds strongly limits the possibility of studying the Th(IV)/thenoate system. This is particularly true for calorimetric titrations where higher concentrations of reagents are required due to relatively small heat effects of the complexation. The percentage of the second complex formed in this case is too low to allow a reasonably accurate estimation of $\Delta \mathrm{H}_{2}$ by numerical elaboration of the experimental data. As a result, the conditions of the calorimetric titrations with the $\mathrm{Th}(\mathrm{IV}) /$ thenoate system were selected so as to observe the maximum heat effect from the formation of ML while the amount of $\mathrm{ML}_{2}$ in solution is minimal $(<2 \%)$. This is the reason why the maximum value of $\bar{n}$ is only $\sim 0.25$ in Figure 2B.

Values of the enthalpy of complexation are summarized in Table 1. It is evident that the complexation of Th(IV) with furoic and thenoic acids is endothermic. It is the large and positive entropy that favors the complexation. As discussed in the literature for hard acid - hard base interactions, ${ }^{18,19}$ the unfavorable enthalpy term largely reflects the energy required for dehydration of both the metal ion and the ligands, while the favorable entropy results from the increase in the degree of disorder in both the primary/secondary solvation spheres and the bulk solvent. Furthermore, the similarity in enthalpy and entropy between $\mathrm{Th}(\mathrm{IV}) /$ furoate and Th(IV)/thenoate complexation implies that the ether oxygen in furoic acid or the sulfur in thenoic acid does not participate in the coordination. This argument is further discussed subsequently in comparison with other carboxylic acids. 


\subsection{Coordination mode in the thorium furoate complexes}

As shown in Table 1, the present model from this work includes only the simple

complexes $\left(\mathrm{ThL}_{\mathrm{j}}^{(4-\mathrm{j})^{+}}\right)$while the previous model ${ }^{3}$ assumes the formation of two protonated complexes ( $\mathrm{ThL}_{4} \mathrm{H}_{2}{ }^{2+}$ and $\left.\mathrm{ThL}_{3} \mathrm{H}_{2}{ }^{3+}\right)$. This difference results in drastically different speciation for the Th(IV)/furoic and Th(IV)/thenoic systems. For example, as Table 2 shows, in Solutions II - IV, the previous model predicts that the uncomplexed furoic acid (HL) ranges from 10 to $33 \%$, while the present model indicates that there is $64-84 \%$ uncomplexed furoic acid in these solutions. Raman and EXAFS experiments were conducted in this work to help clarify the coordination mode in the thorium furoate complexes.

3.3.1 Raman studies. Figure 3 shows the Raman spectra of solutions of furoic acid (HL) and sodium furoate $(\mathrm{NaL})$. A few significant features of the spectra can be summarized as follows: 1) a band at $1702 \mathrm{~cm}^{-1}$ is present in the spectrum for HL, but absent in that for NaL; 2) the band at $1385 \mathrm{~cm}^{-1}$ for HL splits into two for NaL $\left(1395 \mathrm{~cm}^{-}\right.$ ${ }^{1}$ and $1367 \mathrm{~cm}^{-1}$ ); 3) the intensity of the band at $\sim 1480 \mathrm{~cm}^{-1}$ increase when furoic acid is deprotonated. The bands between $1020 \mathrm{~cm}^{-1}$ and $1600 \mathrm{~cm}^{-1}$ are common to furane, furoic acid and furoate ion and can be attributed to the etherocyclic ring based on the information in the literature. ${ }^{20}$ Based on these features, the band at $1702 \mathrm{~cm}^{-1}$ can be assigned to the protonated carboxylate group in protonated furoic acid (HL) and used to determine its concentration in solution.

Raman spectra of Solutions I - IV (see Table 2 for the conditions) are shown in Figure 4 (A). As the concentration of Th(IV) increases from 0 to $253 \mathrm{mmol} \mathrm{dm}^{-3}$, the formation of $\mathrm{Th}(\mathrm{IV}) /$ furoate complexes results in the following changes in the Raman 
spectra: 1) the intensity of the band at $1702 \mathrm{~cm}^{-1}$ decreases; 2) the intensities of the bands at $1585 \mathrm{~cm}^{-1}, 1485 \mathrm{~cm}^{-1}$ and in the range of $1000-1180 \mathrm{~cm}^{-1}$ increase; 3) two shoulders appear in the bands at 1410 and $1140 \mathrm{~cm}^{-1}$. Since the band at $1702 \mathrm{~cm}^{-1}$ is exclusively due to the protonated furoic acid (HL), a quantitative analysis of the band intensity by spectra deconvolution was attempted to estimate the concentration of HL in the four solutions. All the four spectra were deconvoluted. For the three solutions containing Th(IV) (Solutions II - IV), seven peaks were used to obtain a good fit. An example of the deconvoluted peaks is shown in Figure 4 (B). From the deconvoluted spectra, the peak intensities at $1702 \mathrm{~cm}^{-1}$ for the four solutions were calculated. Since the concentration of total furoic acid $\left(C_{\text {furoic }}\right)$ in the four solutions was maintained constant $\left(C_{\text {furoic }}=232 \mathrm{mmol}\right.$ $\mathrm{dm}^{-3}$ ) and $100 \%$ of the furoic acid was in the protonated form (HL) in Solution I, the ratio of the intensities at $1702 \mathrm{~cm}^{-1}$ for Solutions II - IV to that for Solution I gives the mole fraction of the uncomplexed and protonated HL in Solutions II - IV, i.e., ([HL $\left.]_{\text {uncomplexed }} / C_{\text {furoic }}\right)$. Experimental values of $[\mathrm{HL}]_{\text {uncomplexed }} / C_{\text {furoic }}$ obtained from the Raman spectra are listed in Table 2.

The mole fractions of HL calculated from the present model (this work) and the previous model ${ }^{3}$ are also listed in Table 2 for comparison. It is shown that the values calculated by the present model are in good agreement with the experimental values, but the values calculated by the previous model ${ }^{3}$ are much lower. This comparison supports

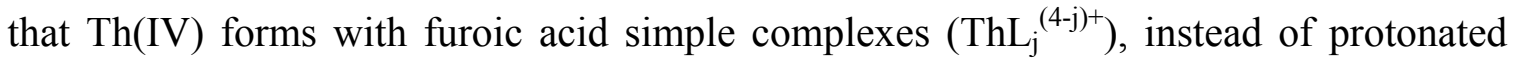
complexes $\left(\mathrm{ThL}_{4} \mathrm{H}_{2}{ }^{2+}\right.$ and $\left.\mathrm{ThL}_{3} \mathrm{H}_{2}{ }^{3+}\right)$ under the experimental conditions. It should be pointed out that the discussions on the Raman results are based on the assumption that, if 
the protonated complexes ever formed, the position, intensity and/or width of the Raman bands of furoic acid would be perturbed to a certain degree.

3.3.2 EXAFS Studies. Carboxylate groups could coordinate metal ions by unidentate or bidentate modes. ${ }^{21,22}$ In the simple complexes between $\mathrm{Th}^{4+}$ and deprotonated monocarboxylate anions (e.g., acetate), the carboxylate group usually coordinates Th(IV) in the bidentate mode. ${ }^{23}$ However, it is not clear what coordination mode the carboxylate would take in the protonated $\mathrm{Th}(\mathrm{IV}) /$ carboxylate complexes because these complexes have not been structurally identified. Nevertheless, it seems unlikely that a protonated carboxylate group could coordinate the metal ion by the bidentate mode. Instead, it would coordinate the metal ion through one oxygen in the unidentate mode.

Literature data on the coordination of $\mathrm{U}(\mathrm{VI})$ with carboxylates ${ }^{24,9}$ show that the bidentate and unidentate carboxylate can be differentiated by two features: (1) the $R_{\mathrm{U}-\mathrm{O}}$ is longer in the former $(\sim 2.45-2.48 \AA)$ than in the latter $(\sim 2.35 \AA)$; (2) the $R_{\mathrm{U}-\mathrm{C}}$ in the former is $\sim 2.85-2.91 \AA$, easily identified by EXAFS. However, detecting the carbon in a unidentate carboxylate may be difficult due to its longer distance $\left(R_{\mathrm{U}-\mathrm{C}} 3.5 \AA\right)$. Based on these literature data, attempts were made in this work to use EXAFS to help clarify the discrepancies between the previous ${ }^{3}$ and present models, i.e., whether protonated complexes (e.g., $\mathrm{ThL}_{3} \mathrm{H}_{2}, \mathrm{ThL}_{4} \mathrm{H}_{2}$ ) are dominant in the $\mathrm{Th}(\mathrm{IV}) /$ furoate system.

The EXAFS spectrum of a Th(IV)/furoic acid solution and its Fourier Transform are shown in Figure 5. Speciation calculations with the previous model ${ }^{3}$ and the present model from this work indicate the following dominant species in this solution: 
Previous model: $\mathrm{ML}(\mathrm{LH})_{2}(89.3 \%), \mathrm{ML}_{2}(\mathrm{LH})_{2}(6.8 \%)$. Average: $\mathrm{ML}_{1.03}(\mathrm{LH})_{2}$

Current model: $\mathrm{ML}$ (43.4\%), $\mathrm{ML}_{2}$ (30.9), $\mathrm{ML}_{3}$ (20.1). Average: $\mathrm{ML}_{1.7}$

The previous model predicts that, by average, there is only one ligand in bidentate mode with Th(IV), but the current model predicts that there are about two ligands in bidentate mode with Th(IV). The best-fit parameters (Table 3) indicate that, in addition to 10 oxygen atoms at $2.46 \AA$, there are 2 carbon atoms at $3.10 \AA$, consistent with the present model from this work. It is noticed that the observed $\mathrm{R}_{\mathrm{Th}-\mathrm{C}}(3.10 \AA)$ is significantly longer than the $\mathrm{R}_{\mathrm{U}-\mathrm{C}}\left(\begin{array}{lll}\sim & 2.90 & \AA\end{array}\right)$ in bidentate $\mathrm{U}(\mathrm{VI}) /$ carboxylate

complexes ${ }^{9,24}$ though the $\mathrm{R}_{\text {Th-O }}(2.46 \AA)$ and $\mathrm{R}_{\mathrm{U}-\mathrm{O}}(2.45 \AA)$ are comparable. Currently we do not have a satisfactory explanation for this observation due to the scarcity of crystallographic data for thorium carboxylate compounds. However, it is interesting to mention that in the solid compounds of tris-carbonato $\mathrm{Th}(\mathrm{IV}){ }^{17}$ and $\mathrm{U}(\mathrm{VI}),{ }^{25}$ the $\mathrm{R}_{\mathrm{Th}-\mathrm{C}}$ $(2.95 \AA)$ and $\mathrm{R}_{\mathrm{Th}-\mathrm{O}}(2.45 \AA)$ are both longer than corresponding $\mathrm{R}_{\mathrm{U}-\mathrm{C}}(2.89 \AA)$ and $\mathrm{R}_{\mathrm{U}-\mathrm{O}}$ $(2.42 \AA)$, probably reflecting the difference in crystal radii between $\mathrm{Th}(\mathrm{IV})$ and $\mathrm{U}(\mathrm{VI})$.

\subsection{Ligand Basicity and $\log \beta-\mathbf{p K}_{\mathrm{a}}$ Correlation}

Figure 6 shows the correlation between the ligand basicity (measure by $\mathrm{pK}_{\mathrm{a}}$ ) and the 1:1 Th(IV) complex formation constants. Data for furoic and thenoic acids fill the gap in the $\mathrm{pK}_{\mathrm{a}}$ range from 2.5 to 3.8 and fit nicely with the linear correlation including other carboxylic acids. This correlation suggests that, as the complexation of Th(IV) with other monocarboxylic acids, the complexation between Th(IV) and furoic/thenoic acids is essentially electrostatic in nature. In addition, the linear correlation with other carboxylic 
acids suggests that the ether oxygen in furoic acid or the sulfur in thenoic acid does not participate in the coordination with Th(IV).

\section{Acknowledgments}

This work was supported by the Ministero dell'Università e della Ricerca Scientifica e Tecnologica (MURST, Rome) within the program COFIN00 (Padova) and the Director, Office of Science, Office of Basic Energy Sciences, Division of Chemical Sciences under U.S. Department of Energy Contract No. DE-AC03-76SF0098 at Lawrence Berkeley National Laboratory (LBNL). The EXAFS experiments were conducted at SSRL, which is operated by the Department of Energy, Division of Chemical Sciences. 


\section{References}

1. A. E. Martell, R. M. Smith, R. M., Critical Stability Constants, Vol. 6, Plenum Press, New York, 1989.

2. P. A. Bertrand, G. R. Choppin, in "Gmelin Handbook of Inorganic Chemistry, U, Suppl. Vol.D1”, edited by Vera Haase and Rudolf Keim, Springer-Verlag, BerlinHeidelberg, 1983, pp.195-279.

3. Jan G. H. du Preez, Gerhard F. J. Swiegers, Chem. Soc., Dalton Trans., 1995, 16, 2697-9.

4. W. L. F. Armarego, D. D. Perrin, Purification of Laboratory Chemicals, Fourth Edition, Butterworth - Heinemann, Oxford 1996.

5. J. A. Dean, Analytical Chemistry Handbook, McGraw-Hill, Inc., New York, 1995, p.3-108.

6. G. Gran, Analyst, 1952, 77, 661 .

7. P. Di Bernardo, A. Cassol, G. Tomat, A. Bismondo, L. Magon, J. Chem. Soc. Dalton, 1983, 733.

8. P. Zanonato, P. Di Bernardo, A. Bismondo, L. Rao, G. R. Choppin, J. Solution Chem. 2001, 30, 1.

9. J. Jiang, L. Rao, P. Zanonato, P. Di Bernardo, A. Bismondo, J. Chem. Soc., Dalton Trans. 2002, 1832-1838.

10. P. Gans, A. Sabatini, A. Vacca, J. Chem. Soc., Dalton Trans. 1985, 1195.

11. A. Cassol, P. Di Bernardo, R. Portanova, M. Tolazzi, \& P.L. Zanonato, J. Chem. Soc. Dalton Trans, 1992, 469.

12. A. Bismondo, A. Cassol, P. Di Bernardo, R. Portanova, M. Tolazzi, P. Zanonato, Ann. Chim. 1999, 89, 185-192.

13. R. Arnek, Arkiv Kemi, 1970, 32, 81.

14. J. J. Bucher, N. M. Edelstein, K. P. Osborne, D. K. Shuh, N. Madden, P. Luke, D. Pehl, C. Cork, D. Malone, P. G. Allen, SRL '95 Conference Proceedings, Rev. Sci. Instr. 1996, 67, 1.

15. G. G. Li, F. Bridges, C. W. Booth, Phys. Rev. B, 1995, 52, 6332.

16. S. I. Zabinsky, J. J. Rehr, A. Ankudinov, R. C. Albers, M. J. Eller, Phys. Rev. B., 1995, 52, 2995. 
17. S. Voliotis, A. Rimsky, Acta Cryst. 1975, B31, 2615.

18. G. Schwarzenbach, Interpretation of solution stabilities of metal complexes, in Proc. Summ. Sch. Stability Constants, $1^{\text {st }}$ (Pub. 1977), (P. Paoletti, R. Barbucci, L. Fabbrizzi, ed.) Ed. Scient. University of Florence, Italy, 1977. pp.151-181.

19. E. N. Rizkalla, G. R. Choppin, in "Handbook on the Physics and Chemistry of Rare Earths, Vol. 18 -Lanthanides/Actinides: Chemistry" (K. A. Gschneider, Jr., L. Eyring, G. R. Choppin, G. H. Lander, ed.) Elsevier Science B.V., New York, 1994.

20. D. Lin-Vien, N. B. Colthup, W. G. Fateley, J. G. Grasselli, The Handbook of Infrared and Raman Characteristic Frequencies of Organic Molecules, Academic Press, San Diego, 1991.

21. D. M. Howatson, B. Morosin, J. Inorg. Nucl. Chem. 1975, 37, 1933.

22. D. H. Templeton, A. Zalkin, H. Ruben, L. K. Templeton, Acta Cryst. 1985, C41, 1439.

23. R. Bressat, B. Claudel, G. Giorgio, B. Mentzen, J. Chim. Phys. Phys.-Chim. Biol. 1968, 65, 1614.

24. M. A. Denecke, T. Reich, S. Pompe, M. Bubner, K. H. Heise, H. Nitsche, P. G. Allen, J. J. Bucher, N. M. Edelstein, D. K. Shuh, J. de Physique IV, 1997, 7, 637.

25. P. G. Allen, J. J. Bucher, D. L. Clark, N. M. Edelstein, S. A. Ekberg, J. W. Gohdes, E. A. Hudson, N. Kaltsoyannis, W. W. Lukens, M. P. Neu, P. D. Palmer, T. Reich, D. K. Shuh, C. D. Tait, B. D. Zwick, Inorg. Chem. 1995, 34, 4797. 
Table 1 Thermodynamic parameters of protonation and complexation for the Th(IV)/furoate and Th(IV)/thenoate systems, $I=1.0 \mathrm{~mol} \mathrm{dm}^{-3}\left(\mathrm{NaClO}_{4}\right)$, the error limits represent $3 \sigma$. Data marked "*" are from Ref.3.

\begin{tabular}{|c|c|c|c|c|c|}
\hline Reaction & Ligand & $\begin{array}{c}\log \beta_{\mathrm{H}} \\
\text { or } \log \beta_{\mathrm{M}}\end{array}$ & $\begin{array}{c}-\Delta G^{o} \\
\mathrm{~kJ} \mathrm{~mol}^{-1}\end{array}$ & $\begin{array}{c}\Delta H^{o} \\
\mathrm{~kJ} \mathrm{~mol}^{-1}\end{array}$ & $\begin{array}{c}\Delta S^{o} \\
\mathrm{~J} \mathrm{~K}^{-1} \mathrm{~mol}^{-1}\end{array}$ \\
\hline \multirow[t]{4}{*}{$\mathrm{H}^{+}+\mathrm{L}^{-}=\mathrm{HL}$} & Furoate & $3.02 \pm 0.01$ & $17.24 \pm 0.06$ & $2.94 \pm 0.04$ & $67.7 \pm 0.3$ \\
\hline & & $3.01 \pm 0.00^{*}$ & & & \\
\hline & Thenoate & $3.36 \pm 0.01$ & $19.18 \pm 0.06$ & $0.70 \pm 0.04$ & $66.7 \pm 0.3$ \\
\hline & & $3.24 \pm 0.00 *$ & & & \\
\hline \multirow[t]{4}{*}{$\mathrm{Th}^{4+}+\mathrm{L}^{-}=\mathrm{ThL}^{3+}$} & Furoate & $3.19 \pm 0.01$ & $18.20 \pm 0.06$ & $11.7 \pm 0.3$ & $100 \pm 1$ \\
\hline & & $2.85 \pm 0.04^{*}$ & & & \\
\hline & Thenoate & $3.24 \pm 0.06$ & $18.5 \pm 0.4$ & $14.15 \pm 0.15$ & $110 \pm 2$ \\
\hline & & $3.04 \pm 0.07^{*}$ & & & \\
\hline \multirow[t]{4}{*}{$\mathrm{Th}^{4+}+2 \mathrm{~L}^{-}=\mathrm{ThL}_{2}^{2+}$} & Furoate & $5.35 \pm 0.01$ & $30.53 \pm 0.06$ & $22.8 \pm 2.1$ & $179 \pm 7$ \\
\hline & & $5.11 \pm 0.07^{*}$ & & & \\
\hline & Thenoate & $5.83 \pm 0.18$ & $33.3 \pm 1.0$ & ------ & ------ \\
\hline & & $5.69 \pm 0.05^{*}$ & & & \\
\hline $\mathrm{Th}^{4+}+3 \mathrm{~L}^{-}=\mathrm{ThL}_{3}^{+}$ & Furoate & $7.47 \pm 0.01$ & $42.63 \pm 0.06$ & $28.3 \pm 2.4$ & $238 \pm 8$ \\
\hline \multirow[t]{2}{*}{$\mathrm{Th}^{4+}+3 \mathrm{~L}^{-}+2 \mathrm{H}^{+}=\mathrm{ThH}_{2} \mathrm{~L}_{3}^{3+}$} & Furoate & $12.78 \pm 0.06^{*}$ & & & \\
\hline & Thenoate & $14.16 \pm 0.05^{*}$ & & & \\
\hline $\mathrm{Th}^{4+}+4 \mathrm{~L}^{-}=\mathrm{ThL}_{4}$ & Furoate & $10.07 \pm 0.03 *$ & & & \\
\hline \multirow[t]{2}{*}{$\mathrm{Th}^{4+}+4 \mathrm{~L}^{-}+2 \mathrm{H}^{+}=\mathrm{ThH}_{2} \mathrm{~L}_{4}{ }^{2+}$} & Furoate & $15.14 \pm 0.07 *$ & & & \\
\hline & Thenoate & $18.00 \pm 0.03 *$ & & & \\
\hline
\end{tabular}


Table 2 Speciation of the Th(IV)/furoate solutions

(HL denotes protonated furoic acid)

\begin{tabular}{ccccccc}
\hline & \multicolumn{2}{c}{$\begin{array}{c}\text { Solution composition } \\
\left(\text { Concentration in mmol } \mathrm{dm}^{-3}\right)\end{array}$} & \multicolumn{3}{c}{$\begin{array}{c}\text { Mole fraction of uncomplexed HL } \\
{[\mathrm{HL}]_{\text {uncomplex }} / \mathrm{C}_{\text {furoic acid }}}\end{array}$} \\
\hline \# & $\mathrm{C}_{\text {furoic acid }}$ & {$\left[\mathrm{HClO}_{4}\right]$} & {$\left[\mathrm{Th}^{4+}\right]$} & $\begin{array}{c}\text { Exp. value } \\
\text { obtained from } \\
\text { Raman }\end{array}$ & $\begin{array}{c}\text { Calculated by } \\
\text { previous } \\
\text { model }\end{array}$ & $\begin{array}{c}\text { Calculated by } \\
\text { present model } \\
\text { (this work) }\end{array}$ \\
\hline I & 372 & 272 & 0 & 1 & 1 & 1 \\
II & 372 & 272 & 84 & 0.85 & 0.33 & 0.84 \\
III & 372 & 272 & 127 & 0.77 & 0.18 & 0.78 \\
IV & 372 & 272 & 253 & 0.71 & 0.10 & 0.64 \\
\hline
\end{tabular}


Table 3 Fitting parameters for Th L3-edge EXAFS.

\begin{tabular}{|c|c|c|c|c|c|}
\hline Samples & Shell & $R, \AA$ & $N^{\mathrm{a}}$ & $\sigma,{ }^{\mathrm{a}} \AA$ & $\Delta E_{0}, \mathrm{eV}$ \\
\hline \multirow{2}{*}{$\mathrm{ThO}_{2}(\mathrm{~s})$} & Th-O & 2.42 & $6.8 \pm 1.0$ & 0.0678 & -17.07 \\
\hline & Th-Th & 3.97 & $10.0 \pm 1.5$ & 0.0581 & -17.07 \\
\hline $\begin{array}{l}\text { Th(IV) perchlorate solution } \\
{[\mathrm{Th}]=50 \mathrm{mmol} \mathrm{dm}^{-3}} \\
{\left[\mathrm{HClO}_{4}\right]=1.0 \mathrm{~mol} \mathrm{dm}^{-3}}\end{array}$ & Th-O & 2.45 & $10.6 \pm 1.0$ & 0.0829 & -9.37 \\
\hline Th(IV) furoate solution & Th-O & 2.46 & $10.2 \pm 0.5$ & 0.0856 & -9.13 \\
\hline $\begin{array}{l}{[\mathrm{Th}]=84 \mathrm{mmol} \mathrm{dm}^{-3}} \\
{\left[\mathrm{HClO}_{4}\right]=272 \mathrm{mmol} \mathrm{dm}^{-3}} \\
{[\text { furoic acid }]=372 \mathrm{mmol} \mathrm{dm}^{-3}}\end{array}$ & Th-C & 3.10 & $1.8 \pm 0.5$ & 0.0500 & -9.13 \\
\hline
\end{tabular}

${ }^{a}$ The $95 \%$ confidence limits for the bond length (R) for each shell are $\pm 0.02 \AA$. The amplitude reduction factor, $S_{0}^{2}$, is 1.00. $\sigma$ is the EXAFS Debye-Waller term which accounts for the effects of thermal and static disorder through damping of the EXAFS oscillations by the factor $\exp \left(-2 k^{2} \sigma^{2}\right)$. 
Figure Captions

Figure 1 Potentiometric titrations of Th(IV)/furoate (top) and Th(IV)/thenoate (bottom) systems. $\mathrm{I}=1.0 \mathrm{~mol} \mathrm{dm}^{-3} \mathrm{NaClO}_{4}$. The curves are calculated using the formation constants in Table 1.50-70 points were collected in each titration. Titration conditions for each set of data are shown in order: $V_{0}\left(\mathrm{~cm}^{3}\right), C_{\mathrm{Th}}$ in cup, $C_{\mathrm{H}}$ in cup, $C_{\mathrm{L}}$ in titrant, $C_{\mathrm{H}}$ in titrant (mmol dm$\left.{ }^{-3}\right)$. (A) For Th(IV)/furoate: (O) 19.09, 4.84, 31.75, 100.2, 49.3; ( $\square$ ) 20.13, 6.12, 6.58, 100.2, 49.3; ( $\Delta$ ) 20.13, 6.12, 31.60, 416.5, 36.7; ( $)$ ) 22.13, 2.77, 26.07, 416.5, 36.7. (B) For Th(IV)/thenoate: (O) 20.63, 5.97, 31.0, 97.7, 47.7; ( $\square$ ) 20.00, 6.12,

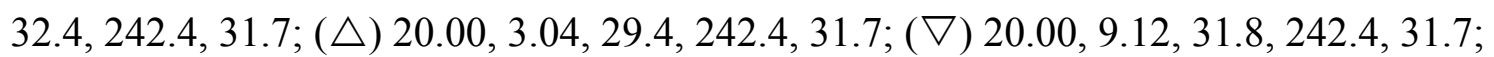
(O) $20.00,31.67,38.9,308.9,9.7$.

Figure 2 Calorimetric titrations of Th(IV)/furoate (top) and Th(IV)/thenoate (bottom) systems. $\mathrm{I}=1.0 \mathrm{~mol} \mathrm{dm}^{-3} \mathrm{NaClO}_{4}$. The curves are calculated using the formation constants and enthalpy of complexation in Table $1.50-70$ points were collected in each titration. $V_{0}=20.0 \mathrm{~cm}^{3}$. Titration concentrations for each set of data are shown in order: $C_{\mathrm{Th}}$ in cup, $C_{\mathrm{H}}$ in cup, $C_{\mathrm{L}}$ in titrant, $C_{\mathrm{H}}$ in titrant $\left(\mathrm{mmol} \mathrm{dm}^{-3}\right)$. (A) For Th(IV)/furoate:

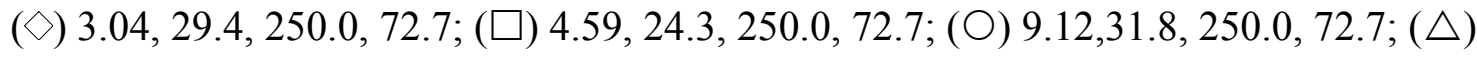
$15.20,16.3,379.5,78.3 ;(\nabla) 30.40,32.7,379.5,78.3 ;(\bigcirc) 6.12,32.4,228.3,228.3 ;(\mathbf{\Delta})$ 15.83, 18.1, 348.4, 348.4; ( $\mathbf{\nabla}) 31.67,36.2,348.4,348.4$. (B) For Th(IV)/thenoate: $(O)$

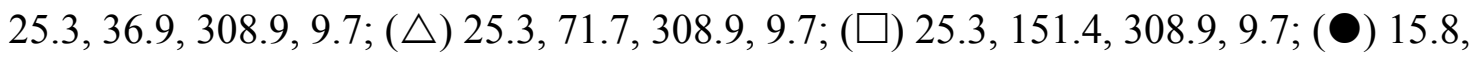
$18.1,308.9,9.7 ;(\square) 31.7,36.2,308.9,9.7$.

Figure 3 Raman spectra of furoic acid (A) and sodium furoate (B). (A) $C_{\text {furoate }}=372$ mmol dm${ }^{-3}, C_{\mathrm{HClO} 4}=644 \mathrm{mmol} \mathrm{dm}^{-3}$; (B) $C_{\text {furoate }}=371.4 \mathrm{mmol} \mathrm{dm}^{-3}, C_{\mathrm{NaOH}}=1000 \mathrm{mmol}$ $\mathrm{dm}^{-3}$.

Figure 4 (A) Raman spectra of four Th(IV)/furoate solutions. For all the four solutions, $C_{\text {furoate }}=372 \mathrm{mmol} \mathrm{dm}^{-3}, C_{\mathrm{HClO} 4}=272 \mathrm{mmol} \mathrm{dm}^{-3}$. From Solution I to IV, $C_{\mathrm{Th}}=0,84$, 126 and $253 \mathrm{mmol} \mathrm{dm}^{-3}$, respectively. (B) Deconvolution of the spectra of Solution IV in the region from 1800 to $1350 \mathrm{~cm}^{-1}$. Thick solid line - experimental spectra; thin solid 
lines - seven component spectra; thick dashed line - summation of all the component spectra.

Figure 5 Thorium L3-edge EXAFS spectrum (A) and its Fourier Transform magnitude (B). Solid line - experimental; dashed line - fit. $C_{\mathrm{Th}}=84 \mathrm{mmol} \mathrm{dm}^{-3} ; C_{\text {furoate }}=372 \mathrm{mmol}$ $\mathrm{dm}^{-3} ; C_{\mathrm{HClO} 4}=272 \mathrm{mmol} \mathrm{dm}^{-3}$.

Figure $6 \log \beta_{\mathrm{ML}}$ vs. pKa for complexation of Th(IV) with carboxylic acids $\left(\log \beta_{\mathrm{ML}}=\right.$ $1.54+0.505 \mathrm{pKa})$. 
Figure Captions

Figure 1 Potentiometric titrations of Th(IV)/furoate (top) and Th(IV)/thenoate (bottom) systems. $\mathrm{I}=1.0 \mathrm{~mol} \mathrm{dm}^{-3} \mathrm{NaClO}_{4}$. The curves are calculated using the formation constants in Table 1.50-70 points were collected in each titration. Titration conditions for each set of data are shown in order: $V_{0}\left(\mathrm{~cm}^{3}\right), C_{\mathrm{Th}}$ in cup, $C_{\mathrm{H}}$ in cup, $C_{\mathrm{L}}$ in titrant, $C_{\mathrm{H}}$ in titrant (mmol dm$\left.{ }^{-3}\right)$. (A) For Th(IV)/furoate: (O) 19.09, 4.84, 31.75, 100.2, 49.3; ( $\square$ ) 20.13, 6.12, 6.58, 100.2, 49.3; ( $\Delta$ ) 20.13, 6.12, 31.60, 416.5, 36.7; ( $)$ ) 22.13, 2.77, 26.07, 416.5, 36.7. (B) For Th(IV)/thenoate: (O) 20.63, 5.97, 31.0, 97.7, 47.7; ( $\square$ ) 20.00, 6.12,

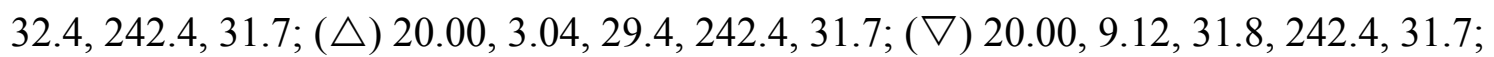
(O) $20.00,31.67,38.9,308.9,9.7$.

Figure 2 Calorimetric titrations of Th(IV)/furoate (top) and Th(IV)/thenoate (bottom) systems. $\mathrm{I}=1.0 \mathrm{~mol} \mathrm{dm}^{-3} \mathrm{NaClO}_{4}$. The curves are calculated using the formation constants and enthalpy of complexation in Table $1.50-70$ points were collected in each titration. $V_{0}=20.0 \mathrm{~cm}^{3}$. Titration concentrations for each set of data are shown in order: $C_{\mathrm{Th}}$ in cup, $C_{\mathrm{H}}$ in cup, $C_{\mathrm{L}}$ in titrant, $C_{\mathrm{H}}$ in titrant $\left(\mathrm{mmol} \mathrm{dm}^{-3}\right)$. (A) For Th(IV)/furoate:

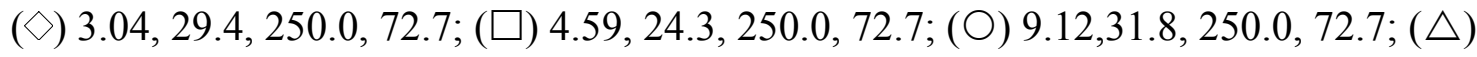
$15.20,16.3,379.5,78.3 ;(\nabla) 30.40,32.7,379.5,78.3 ;(\bigcirc) 6.12,32.4,228.3,228.3 ;(\mathbf{\Delta})$ 15.83, 18.1, 348.4, 348.4; ( $\mathbf{\nabla}) 31.67,36.2,348.4,348.4$. (B) For Th(IV)/thenoate: $(O)$

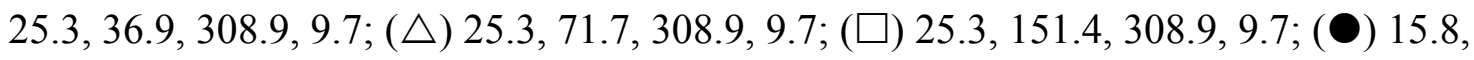
$18.1,308.9,9.7$; (ם) 31.7, 36.2, 308.9, 9.7.

Figure 3 Raman spectra of furoic acid (A) and sodium furoate (B). (A) $C_{\text {furoate }}=372$ mmol dm${ }^{-3}, C_{\mathrm{HClO} 4}=644 \mathrm{mmol} \mathrm{dm}^{-3}$; (B) $C_{\text {furoate }}=371.4 \mathrm{mmol} \mathrm{dm}^{-3}, C_{\mathrm{NaOH}}=1000 \mathrm{mmol}$ $\mathrm{dm}^{-3}$.

Figure 4 (A) Raman spectra of four Th(IV)/furoate solutions. For all the four solutions, $C_{\text {furoate }}=372 \mathrm{mmol} \mathrm{dm}^{-3}, C_{\mathrm{HClO} 4}=272 \mathrm{mmol} \mathrm{dm}^{-3}$. From Solution I to IV, $C_{\mathrm{Th}}=0,84$, 126 and $253 \mathrm{mmol} \mathrm{dm}^{-3}$, respectively. (B) Deconvolution of the spectra of Solution IV in the region from 1800 to $1350 \mathrm{~cm}^{-1}$. Thick solid line - experimental spectra; thin solid 
lines - seven component spectra; thick dashed line - summation of all the component spectra.

Figure 5 Thorium L3-edge EXAFS spectrum (A) and its Fourier Transform magnitude (B). Solid line - experimental; dashed line - fit. $C_{\mathrm{Th}}=84 \mathrm{mmol} \mathrm{dm}^{-3} ; C_{\text {furoate }}=372 \mathrm{mmol}$ $\mathrm{dm}^{-3} ; C_{\mathrm{HClO} 4}=272 \mathrm{mmol} \mathrm{dm}^{-3}$.

Figure $6 \log \beta_{\mathrm{ML}}$ vs. pKa for complexation of Th(IV) with carboxylic acids $\left(\log \beta_{\mathrm{ML}}=\right.$ $1.54+0.505 \mathrm{pKa})$. 

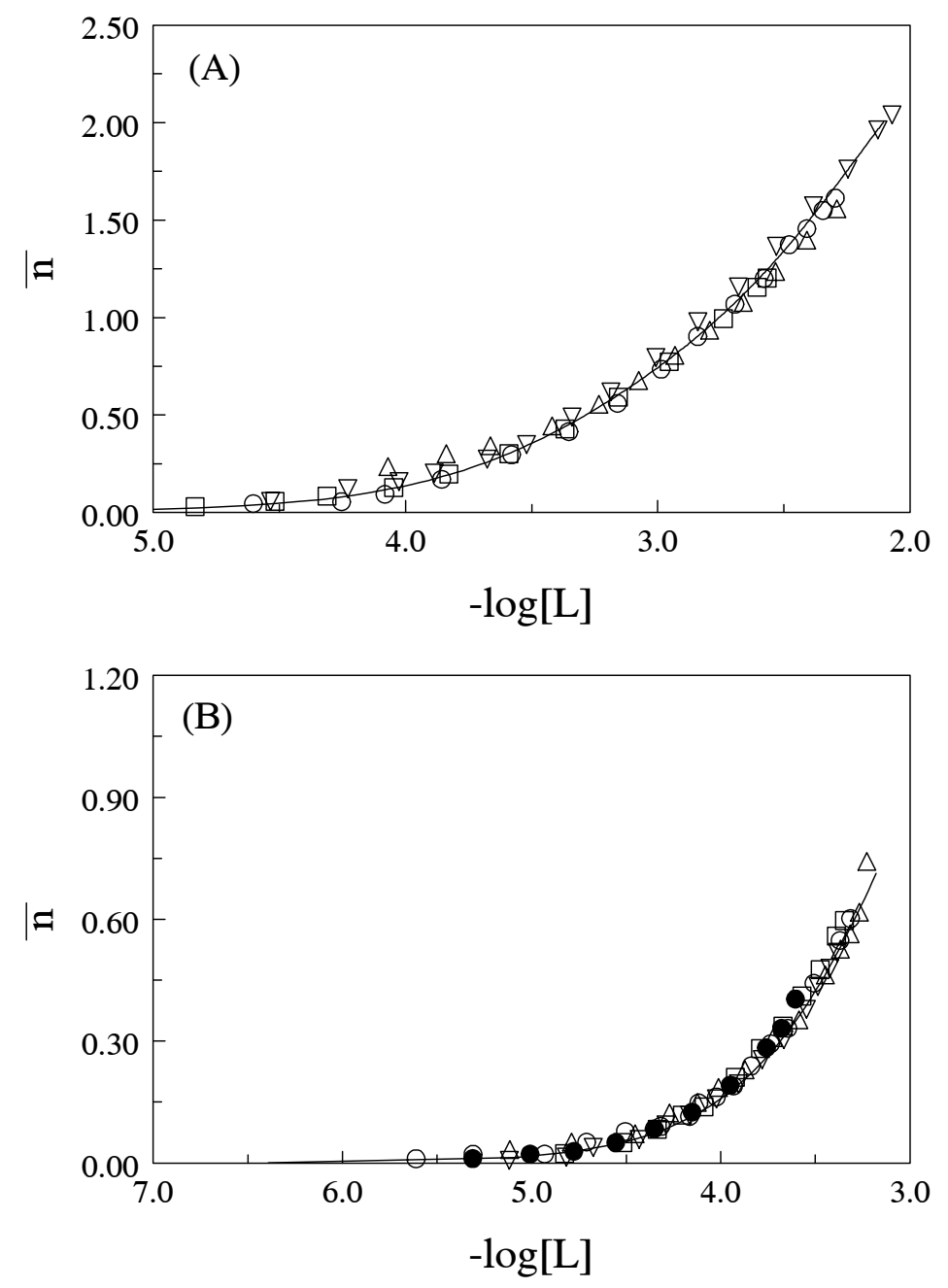

Figure 1 Potentiometric titrations of Th(IV)/furoate (top) and Th(IV)/thenoate (bottom) systems. $\mathrm{I}=1.0 \mathrm{~mol} \mathrm{dm}^{-3} \mathrm{NaClO}_{4}$. The curves are calculated using the formation constants in Table $1.50-70$ points were collected in each titration. Titration conditions for each set of data are shown in order: $V_{0}\left(\mathrm{~cm}^{3}\right), C_{\mathrm{Th}}$ in cup, $C_{\mathrm{H}}$ in cup, $C_{\mathrm{L}}$ in titrant, $C_{\mathrm{H}}$ in titrant (mmol dm${ }^{-3}$ ). (A) For Th(IV)/furoate: (O) 19.09, 4.84, 31.75, 100.2, 49.3; ( $\square$ ) $20.13,6.12,6.58,100.2,49.3 ;(\Delta) 20.13,6.12,31.60,416.5,36.7$; ( $)$ ) 22.13, 2.77, 26.07, 416.5, 36.7. (B) For Th(IV)/thenoate: (O) 20.63, 5.97, 31.0, 97.7, 47.7; ( $\square$ ) 20.00, 6.12, 32.4, 242.4, 31.7; $\triangle$ ( ) 20.00, 3.04, 29.4, 242.4, 31.7; ( $\nabla)$ 20.00, 9.12, 31.8, 242.4, 31.7; (O) $20.00,31.67,38.9,308.9,9.7$. 

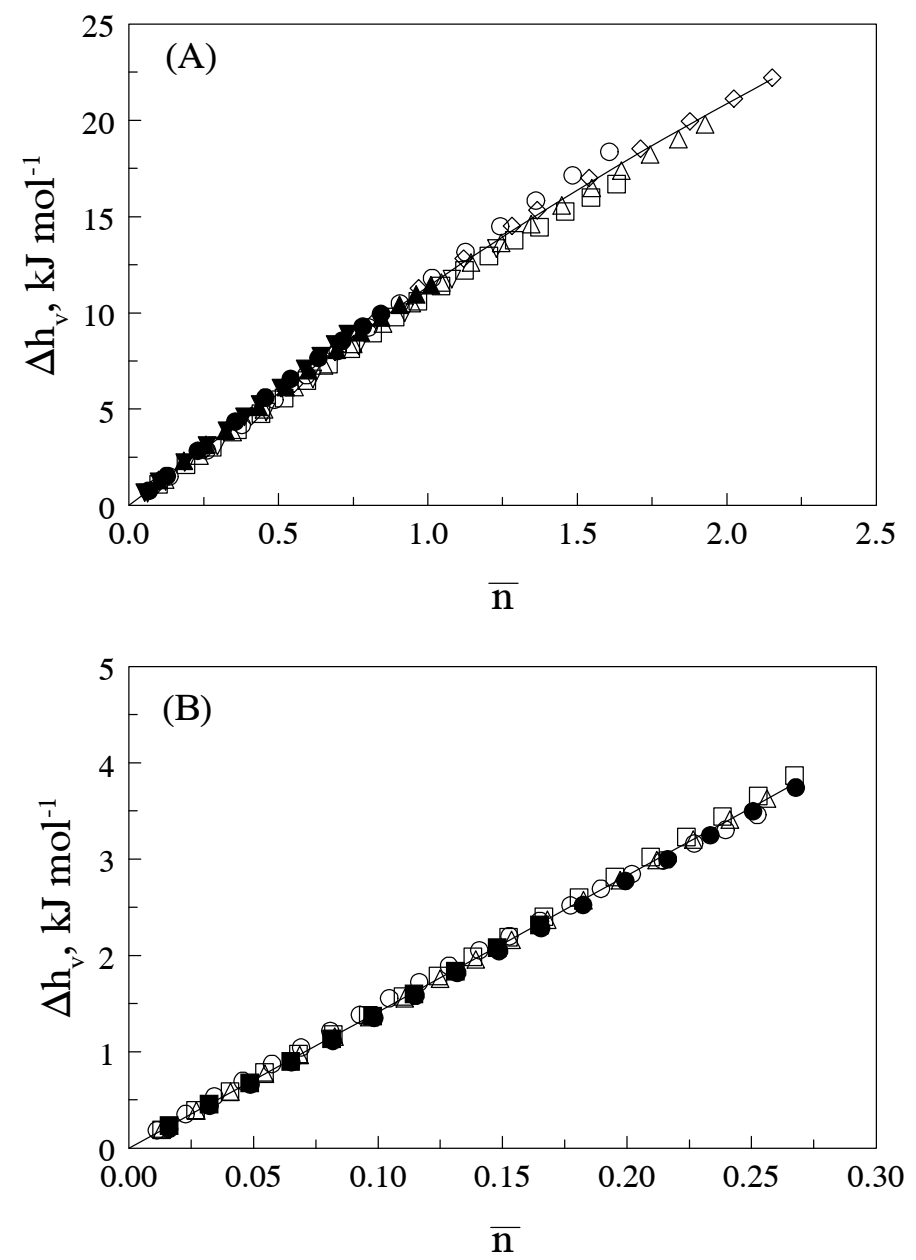

Figure 2 Calorimetric titrations of Th(IV)/furoate (top) and Th(IV)/thenoate (bottom) systems. $\mathrm{I}=1.0 \mathrm{~mol} \mathrm{dm}^{-3} \mathrm{NaClO}_{4}$. The curves are calculated using the formation constants and enthalpy of complexation in Table $1.50-70$ points were collected in each titration. $V_{0}=20.0 \mathrm{~cm}^{3}$. Titration concentrations for each set of data are shown in order: $C_{\mathrm{Th}}$ in cup, $C_{\mathrm{H}}$ in cup, $C_{\mathrm{L}}$ in titrant, $C_{\mathrm{H}}$ in titrant $\left(\mathrm{mmol} \mathrm{dm}^{-3}\right)$. (A) For Th(IV)/furoate: $(\diamond) 3.04,29.4,250.0,72.7 ;(\square) 4.59,24.3,250.0,72.7$; (○) 9.12,31.8, 250.0, 72.7; $(\triangle)$ $15.20,16.3,379.5,78.3 ;(\nabla) 30.40,32.7,379.5,78.3 ;(\bullet) 6.12,32.4,228.3,228.3 ;(\mathbf{\Delta})$ 15.83, 18.1, 348.4, 348.4; ( $\mathbf{\nabla}) 31.67,36.2,348.4$, 348.4. (B) For Th(IV)/thenoate: (O)

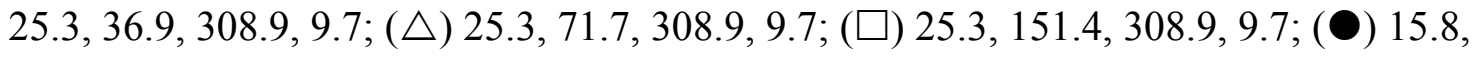
$18.1,308.9,9.7 ;$ (ロ) 31.7, 36.2, 308.9, 9.7. 


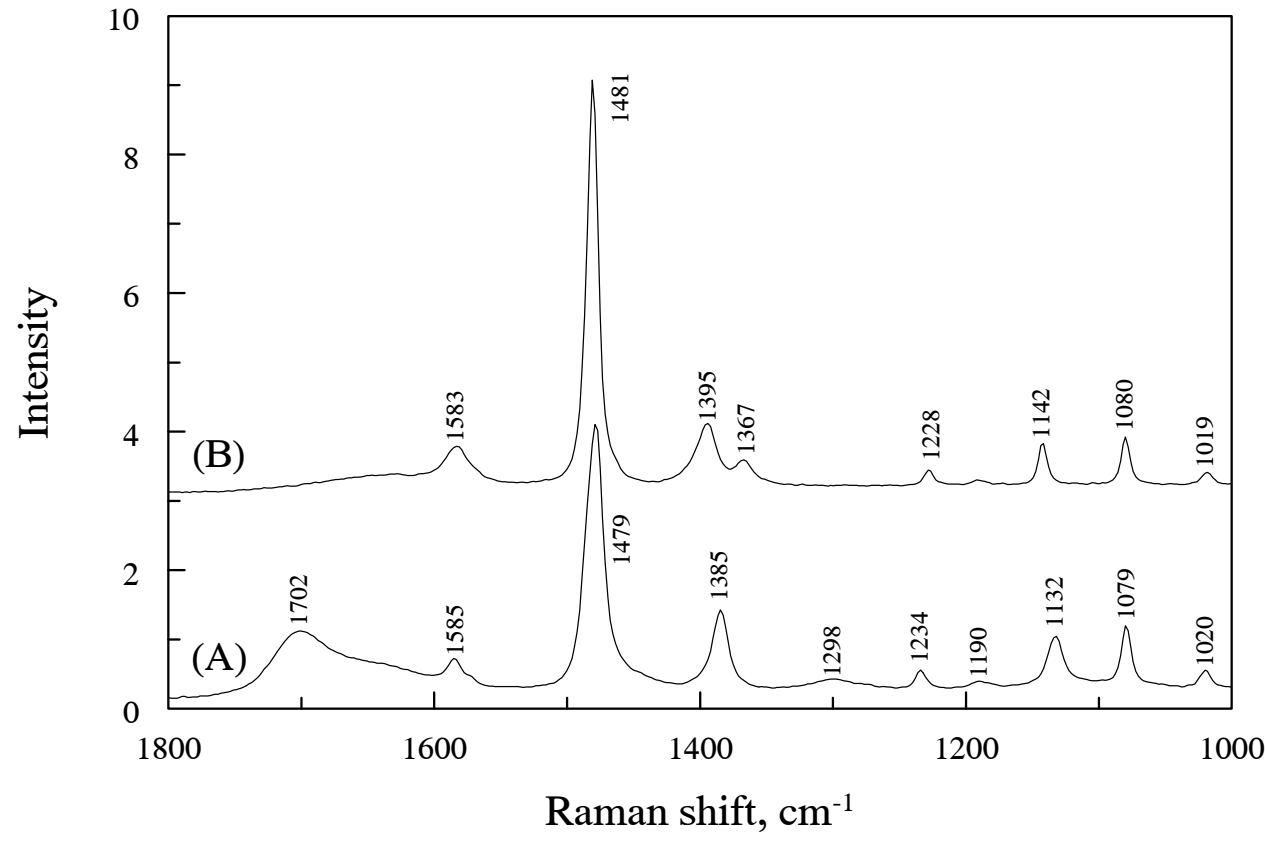

Figure 3 Raman spectra of furoic acid (A) and sodium furoate (B). (A) $C_{\text {furoate }}=372$

mmol dm${ }^{-3}, C_{\mathrm{HClO} 4}=644 \mathrm{mmol} \mathrm{dm}^{-3}$; (B) $C_{\text {furoate }}=371.4 \mathrm{mmol} \mathrm{dm}^{-3}, C_{\mathrm{NaOH}}=1000 \mathrm{mmol}$ $\mathrm{dm}^{-3}$. 

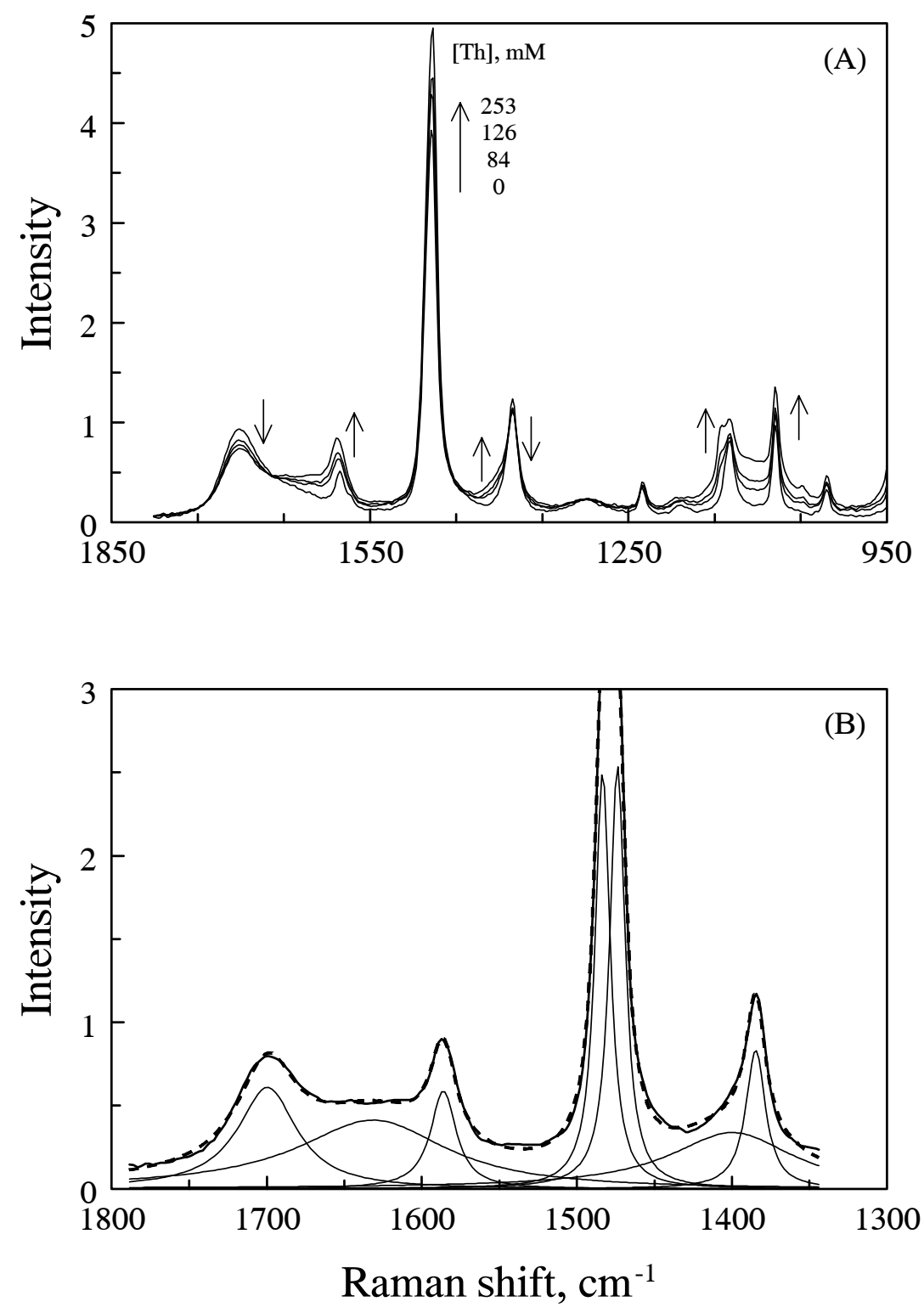

Figure 4 (A) Raman spectra of four Th(IV)/furoate solutions. For all the four solutions, $C_{\text {furoate }}=372 \mathrm{mmol} \mathrm{dm}^{-3}, C_{\mathrm{HClO} 4}=272 \mathrm{mmol} \mathrm{dm}^{-3}$. From Solution I to IV, $C_{\mathrm{Th}}=0,84$, 126 and $253 \mathrm{mmol} \mathrm{dm}^{-3}$, respectively. (B) Deconvolution of the spectra of Solution IV in the region from 1800 to $1350 \mathrm{~cm}^{-1}$. Thick solid line - experimental spectra; thin solid lines - seven component spectra; thick dashed line - summation of all the component spectra. 

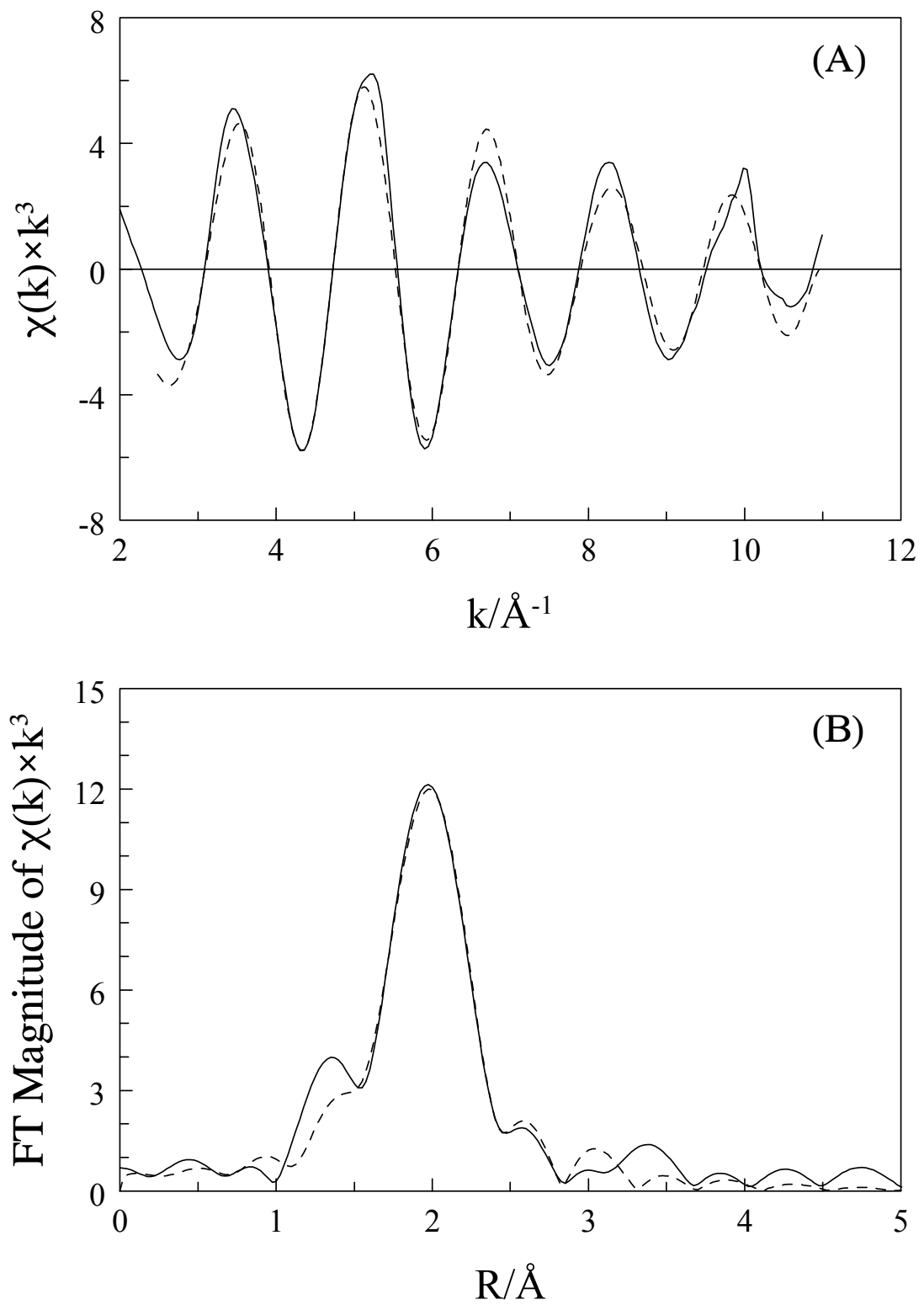

Figure 5 Thorium L3-edge EXAFS spectrum (A) and its Fourier Transform magnitude (B). Solid line - experimental; dashed line - fit. $C_{\mathrm{Th}}=84 \mathrm{mmol} \mathrm{dm}^{-3} ; C_{\text {furoate }}=372 \mathrm{mmol}$ $\mathrm{dm}^{-3} ; C_{\mathrm{HClO} 4}=272 \mathrm{mmol} \mathrm{dm}^{-3}$. 


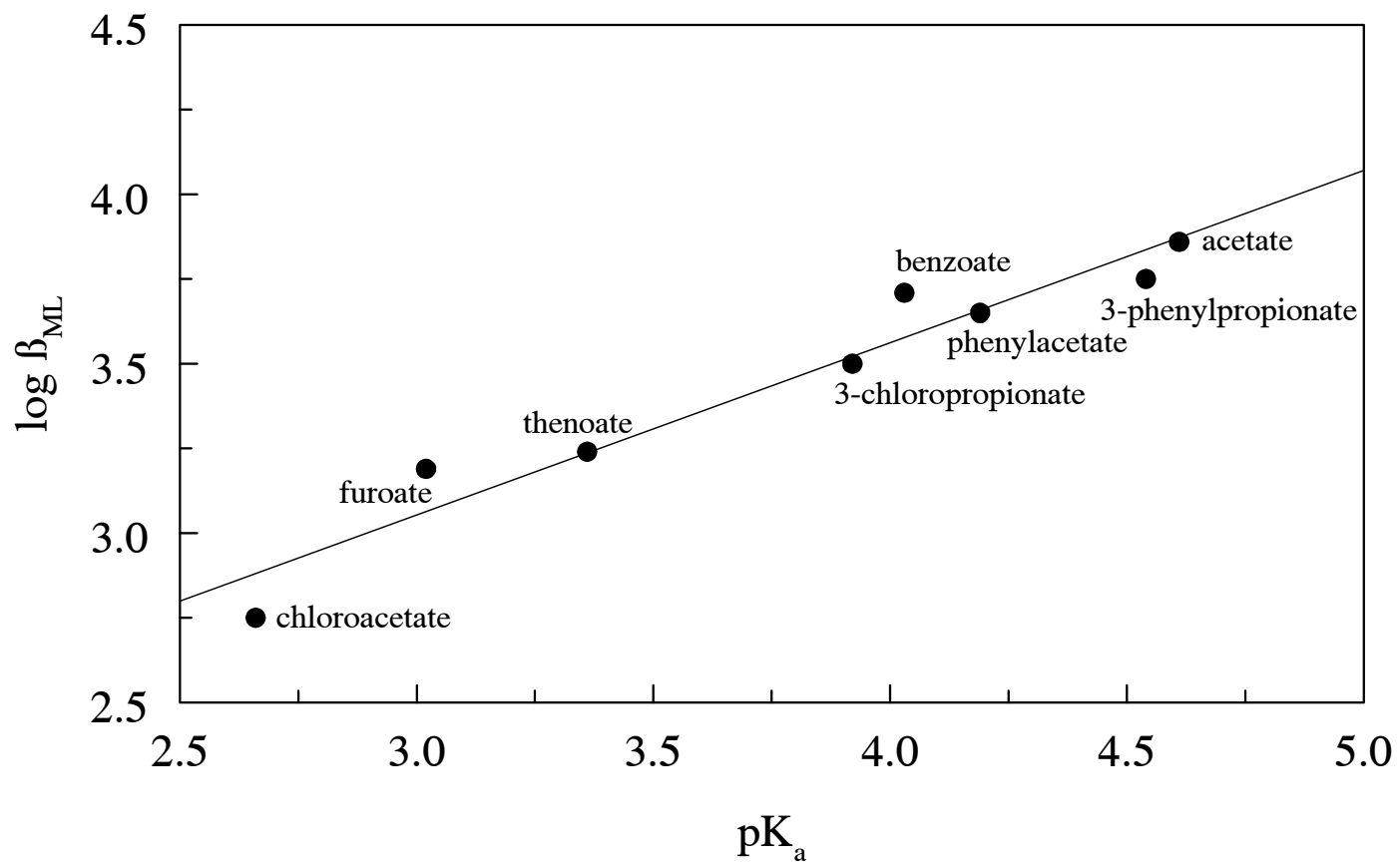

Figure $6 \log \beta_{\mathrm{ML}}$ vs. pKa for complexation of Th(IV) with carboxylic acids $\left(\log \beta_{\mathrm{ML}}=\right.$ $1.54+0.505 \mathrm{pKa})$. 